Short report

\title{
Domestic violence against elderly with disability
}

\author{
Sofia Lalanda Frazão a, b, c, d, *, f, Marília Santos Silva ${ }^{\text {a, f }}$, Pedro Norton ${ }^{\text {e, }}$ \\ Teresa Magalhães ${ }^{\text {a, b, c, d }}$ \\ a Department of Forensic and Legal Medicine, Faculty of Medicine of the University of Porto, Portugal \\ ${ }^{\mathrm{b}}$ North Branch of the National Institute of Legal Medicine and Forensic Sciences of Portugal, Porto, Portugal \\ ${ }^{\mathrm{c}}$ Abel Salazar Biomedical Science Institute, Porto, Portugal \\ ${ }^{\mathrm{d}}$ Forensic Science Center - CENCIFOR, Portugal \\ e Institute of Public Health, Faculty of Medicine of the University of Porto, Portugal
}

\section{A R T I C L E I N F O}

\section{Article history:}

Received 12 May 2014

Received in revised form

14 August 2014

Accepted 3 September 2014

Available online 1 October 2014

\section{Keywords:}

Domestic violence

Abuse

Elder

Disability

\begin{abstract}
A B S T R A C T
Abuse against elders with disabilities is a growing problem as the world population ages. Though they require mandatory reporting, these cases are most frequently not detected or not reported by health professionals for a variety of reasons, including the difficulty of making an accurate diagnosis. By performing a retrospective analysis of alleged domestic violence cases against elders with moderate or severe disability, presented to medical forensic examination at the North Branch of the National Institute of Legal Medicine and Forensic Sciences of Portugal, in Porto, between 2005 and 2013 ( $n=70$ ), we aimed to improve our knowledge of some demographic and forensic characteristics of these cases as well as improve their detection and prevention. The most frequently reported type of abuse was physical (86\%), allegedly perpetrated by male abusers (63\%) living with their victims (90\%), who were most commonly their children (47\%) or partners (49\%; when victims are married). The victims were most frequently female (63\%) who had motor disabilities (49\%) and presented a history of previous episodes of abuse in $74 \%$ of cases; however, only $28 \%$ were previously reported. The physical consequences were most frequently minor injuries (95\%) with permanent consequences (scars) in only $6.8 \%$ of the cases. The injuries were multiple in the majority of the cases (64\%), and the preferred locations were the head and neck (75\%). Elderly females with motor disabilities appear to have a greatest risk of domestic violence, which translates, most frequently, into multiple injuries that are mainly in the head and neck.
\end{abstract}

๑) 2014 Elsevier Ltd and Faculty of Forensic and Legal Medicine. All rights reserved.

\section{Introduction}

The most consensual definition, adopted by the World Health Organization, describes elder abuse as a single or repeated act or lack of appropriate action within any relationship in which there is an expectation of trust or dependence that causes harm or distress to older people, contributing to decreased quality of life, increased morbidity, reduced survival and increased risk of death., ${ }^{1,2}$

The use of different definitions, as well as the sampling and survey methods, applied to different populations makes it difficult to compare studies, describe elder abuse and estimate its prevalence. ${ }^{2-5}$ The values range from $3.2 \%$ to $27.5 \%$ in general population studies from different countries. ${ }^{5}$

\footnotetext{
* Corresponding author. Faculty of Medicine of Porto University, Al. Prof. Hernani Monteiro, 4200-319 Porto, Portugal. Tel.: +351 938464859.

E-mail address: lalanda77@hotmail.com (S.L. Frazão).

f These authors contributed equally to this work.
}

Some experts believe that the incidence and prevalence of elder abuse is increasing, but it is not known whether this growth is due to improved recognition and reporting or to an actual escalation in the number of cases. What is clear is that elder abuse cases will become more frequent as the world population ages. In Portugal, from 2001 to 2011, the population under the age of 15 decreased from $16 \%$ to $15 \%$ of the total population with a simultaneous increase in the population over the age of 65 from $16 \%$ to $19 \%,{ }^{6}$ marking a shift in the age pyramid that had already been predicted and that is expected to worsen in the context of the higher longevity and decreased birth rate.

Although most elders are autonomous and independent, older populations have a higher prevalence of health disorders and increased consequences of accidents. According to the elder-abuse literature, mental illness, ${ }^{7-11}$ poor physical health ${ }^{12-14}$ or poor health in general $^{15}$ are the risk factors for abuse. Elders with physical and/or mental disability are at an even higher risk as they have inherent limitations in daily living activities ${ }^{12,16,17}$ that make them completely or partially dependent, ${ }^{5}$ and, in many cases, 
isolated from society. Lower physical resistance to violence, lower capacity to escape from it and/or higher difficulty understanding and reporting the abuse $\mathrm{e}^{2,13,18}$ are also possible explanations for the increased risk of abuse in the elderly with disabilities. Abuse against these elders is, therefore, an expected event in the aging population wherein $50 \%$ of people 65 years of age or older in Portugal report that they have substantial difficulty performing at least one of six activities of daily living (seeing, hearing, walking, memory/concentration, bathing/dressing, and understanding/ making themselves understood). ${ }^{6}$

Elder abuse is most frequently perpetrated by family members, ${ }^{2}$ which may consist of domestic violence cases. This could be partly explained by the higher levels of stress, burnout and financial problems affecting the caregivers ${ }^{1,3,4}$ that can even lead to deadly consequences. $^{19}$

Notwithstanding the fact that elders with health problems frequently visit their physicians, who are in a privileged position to detect and report cases of elder abuse, only $2 \%$ of suspected cases are reported by physicians according to one study. ${ }^{20}$ In Portugal, domestic violence constitutes a "public crime", allowing the Public Prosecutor Office to institute criminal proceedings even though the victim does not express will or does not want them to press charges; in these cases, public employees have the legal obligation to report every suspected case that they come to acknowledge during their professional activity. Moreover, according to the 53rd article of the Ethics' Code of the Portuguese Medical Association, all physicians have the obligation to report these cases to the authorities. However, in addition to the difficulty of distinguishing the symptoms and signs of abuse from age-related or other disorders while making the differential diagnosis, physicians fail to report for to a variety of other reasons that might include the following, among others ${ }^{2,3,21}$ : (a) unawareness of the obligation to report; (b) unawareness of the available victim support in the community, considering that the victim may be more endangered if the abuse is reported; (c) time limitations that make them choose solving the patient's other problems; (d) preference to keep the patient- physician relationship when the patient does not want to report the abuse; and (e) fear of implication in a legal process. Among cases involving a moderate or severe disability, these patients are frailer and at an increased risk, and there may be greater difficulty in making the correct diagnosis and, consequently, the report. Due to their characteristics, these cases deserve special attention for its detection.

The aim of this study is to promote improved knowledge about some demographic and forensic characteristics of domestic violence perpetrated against elderly people who present with physical and/or mental disabilities that make them dependent and/ or without autonomy to improve the detection and prevention of these cases.

\section{Material and methods}

A retrospective analysis of clinical forensic medical reports was performed. The cases' inclusion criteria were the following: (a) alleged victims of abuse by a family member (with or without cohabitation); (b) 65 years of age or older; (c) presenting, prior to the suspected episode of abuse, a moderate or severe physical and/ or mental disability, corresponding to a rate disability higher than $60 \%$ (determined according to the Portuguese National Table of Disabilities - annex 1 of the Decree-Law 352/2007, of 23rd of October) or to a disability that conditioned dependency or loss of autonomy for daily living activities; (d) having been submitted to a forensic medical examination; (e) at the North Branch of the National Institute of Legal Medicine and Forensic Sciences of Portugal, in Porto; and (f) between 2005 and 2013.
A total of 1278 forensic medical reports related to alleged intrafamilial elder abuse were analysed, 70 of which were selected according to the above criteria.

Data extracted from reports included the characterisation of: (a) the alleged victim's and abuser's socio-demographics; (b) the relationship between the alleged victim and abuser; (c) the type of disability presented by the victim; (d) previous episodes of violence perpetrated by the same alleged abuser; and (e) the episode of abuse that motivated the report and consequent forensic medical examination, namely its type, the resultant injuries, the need for medical treatment and the existence of permanent physical consequences.

For all types of abuse, psychological abuse generally exists simultaneously with the other types; therefore, this type of abuse was only described when it occurred in isolation.

Victims were divided into 2 groups depending on their degree of disability: (a) moderate (when they had autonomy with some dependency, excluding third person dependence) and (b) severe (when they were dependent on a third person). Victims' disabilities were categorised in 5 groups, corresponding to: (a) mental; (b) motor; (c) sensorial; (d) other disabilities; and (e) multiple disabilities (when more than one type was present).

Analysis was performed with SPSS (Statistical Package for Social Science - SPPS INC, Chicago, Illinois, USA) version 21.0, for Windows and was restricted to individuals with complete data on all variables required for a particular analysis.

We conducted univariate analysis to examine the unadjusted relations between all variables of interest. To assess differences between groups, we used chi-square tests for categorical variables and Fisher's test when necessary. Statistical significance was indicated by $p$ values of less than 0.05 .

\section{Results}

Elder people with moderate or severe disability represent $5.5 \%$ of all cases of alleged elder abuse presented for forensic medical examination at the North Branch of the National Institute of Legal Medicine and Forensic Sciences of Portugal, in Porto.

\subsection{Victims' and abusers' socio-demographic characteristics}

Victims' and abusers' socio-demographic characteristics are presented in Table 1 . Victims were mostly female ( $n=44,62.9 \%$ ), married (52.9\%) and retired (94.3\%) and the majority presented with moderate disability (55.7\%). The mean age was 76.94 years old $(S D=7.689$; median = 76; Min. =65; Max. =95), and male and female victims had approximately the same mean age (mean $=75$, $\mathrm{SD}=8$ vs. mean $=78, \mathrm{SD}=8$ ). The proportion of severe disability was higher in female victims (56.8\% vs. $23.1 \% ; p=0.006)$ and in victims older than 74 years of age ( $57.5 \%$ vs. $26.7 \% ; p=0.010$ ).

The abusers were male in $62.9 \%(n=44)$. There was no significant relationship between the abuser's and victim's sex $(p=0.087)$. Their mean age was 52.53 years old $(\mathrm{SD}=16.626$; median $=50 ;$ Min. $=20$; Max. $=88$ ). In the 28 cases with available information, none of the abusers had a professional activity. Information about substance abuse was included in 24 reports (75\% referred to substance abuse) and alcohol was the most frequent substance $(n=13)$. Information about psychiatric disorders was included in 11 reports, and $72.7 \%$ of victims referred to their abusers as having some sort of this type of pathology.

Table 2 presents the relationship between the alleged victims and abusers in the total sample and in married victims $(n=37)$. When considering the totality of the cases, the majority were allegedly perpetrated by the victim's children ( $47.1 \%$ vs. $28.6 \%$ for partners), and within married victims, partners were responsible 
Table 1

Victims' and abusers' socio-demographic data.

\begin{tabular}{|c|c|c|c|}
\hline & & $\begin{array}{l}\text { Victims } \\
(n=70) \\
n(\%)\end{array}$ & $\begin{array}{l}\text { Abusers } \\
(n=70) \\
n(\%)\end{array}$ \\
\hline \multirow{4}{*}{ Marital status } & Married & 37 (52.9) & - \\
\hline & Widowed & $25(35.7)$ & - \\
\hline & Divorced & $5(7.1)$ & - \\
\hline & Single & $3(4.3)$ & - \\
\hline \multirow[t]{4}{*}{ Professional activity } & Retired & $66(94.3)$ & $9(32.1)^{a}$ \\
\hline & Without activity & $4(5.7)$ & $1(3.6)^{\mathrm{a}}$ \\
\hline & Unemployed & 0 & $18(64.3)^{\mathrm{a}}$ \\
\hline & Without information & 0 & $42(60)$ \\
\hline \multirow[t]{2}{*}{ Degree of disability } & Moderate & $39(55.7)$ & - \\
\hline & Severe & $31(44.3)$ & - \\
\hline \multirow[t]{3}{*}{ Substance abuse } & Yes & - & $18(75.0)^{\mathrm{a}}$ \\
\hline & No & - & $6(25.0)^{\mathrm{a}}$ \\
\hline & Without information & - & $46(65.7)$ \\
\hline \multirow[t]{3}{*}{ Psychiatric disorders } & Yes & - & $8(72.7)^{a}$ \\
\hline & No & - & $3(27.3)^{\mathrm{a}}$ \\
\hline & Without information & - & $59(84.3)$ \\
\hline
\end{tabular}

a Valid percent.

for $48.6 \%$ of cases (vs. $32.4 \%$ for children). In 58 cases for which there was information, $89.7 \%(n=52)$ of the abusers were living with the victims.

\subsection{Victims' disability characterisation}

The proportion and description of the different types of disabilities is described in Table 3. Motor disability was the most frequent disability the victims presented with, corresponding to $48.6 \%$ of cases, which was followed by multiple disabilities (30\%). We found the following rates for each type of disability (single or multiple; $n=95)$ : motor $-77.1 \%(n=54)$; mental $-24.3 \%(n=17)$; sensorial $-22.9 \%(n=16)$; others $-11.4 \%(n=8)$.

\subsection{Description of previous episodes of abuse by the same alleged abuser}

There was information about previous episodes of abuse by the same alleged abuser in $74.3 \%(n=52)$ of the forensic medical reports. Table 4 presents the descriptive statistics of the previous episodes of abuse. The periodicity of abuse was specified in 29 of those and $93.1 \%$ of victims referred to having been frequently abused; 25 specified its duration and $40 \%$ mentioned it was longer than 10 years; 42 cited previous reports and 31\% $(n=13)$ of those described that abuse had occurred; and 8 reports had been made by the victim. There was no significant relationship between the victims' background of violence and the victims' $\operatorname{sex}(p=1.000)$ or the disability degree $(p=0.611)$.

In 51 cases for which it was possible to determine the category of previous abuses and consider the association between multiple types of abuse, the most frequent type was physical abuse $(n=41)$, which was followed by financial $(n=11)$, psychological (when isolated; $n=8)$ and sexual types $(n=1)$. Of these cases, neglect was observed simultaneously with 9 cases of physical abuse, 4 of

Table 2

Relationship between the victim and abuser.

\begin{tabular}{lcl}
\hline Relationship & $\begin{array}{l}\text { Total }(n=70) \\
n(\%)\end{array}$ & $\begin{array}{l}\text { Married victims }(n=37) \\
n(\%)\end{array}$ \\
\hline Partner & $20(28.6)$ & $18(48.6)$ \\
Children & $33(47.1)$ & $12(32.4)$ \\
Children-in-law & $10(14.3)$ & $3(8.1)$ \\
Grandchildren & $5(7.1)$ & $3(8.1)$ \\
Other & $2(2.9)$ & $1(2.7)$ \\
\hline
\end{tabular}

Table 3

Victims' disability characterisation $(n=70)$.

\begin{tabular}{|c|c|c|}
\hline & $n(\%)$ & Type of disability \\
\hline Motor & $34(48.6)$ & $\begin{array}{l}\text { MSP }(n=18) \text {; MSP and hemiparesis }(n=3) \text {; } \\
\text { MSP and monoparesis }(n=1) \text {; MSP and ataxia } \\
(n=1) \text {; hemiparesis }(n=4) ; \text { monoparesis } \\
(n=3) \text {; Parkinson's disease }(n=3) \text {; and } \\
\text { hemiparesis and dysarthria }(n=1)\end{array}$ \\
\hline Sensorial & $6(8.6)$ & $\begin{array}{l}\text { Decreased visual acuity }(n=3) \text {; decreased } \\
\text { hearing acuity }(n=1) \text {; amaurosis }(n=1) \text {; and } \\
\text { bilateral deafness }(n=1)\end{array}$ \\
\hline Mental & $5(7.1)$ & $\begin{array}{l}\text { NSD }(n=3) \text {; Alzheimer's disease }(n=1) \text {; and } \\
\text { aphasia }(n=1)\end{array}$ \\
\hline Other & $4(5.7)$ & $\begin{array}{l}\text { Renal failure }(n=2) \text { and respiratory failure } \\
(n=2)\end{array}$ \\
\hline Multiple & $21(30)$ & $\begin{array}{l}\text { NSD and MSP }(n=4) \text {; NSD with aphasia and } \\
\text { ataxia }(n=1) \text {; Alzheimer's disease and MSP } \\
(n=1) \text {; Parkinson's disease with dementia and } \\
\text { MSP }(n=1) \text {; Alzheimer's disease and decreased } \\
\text { hearing acuity ( } n=1) \text {; hemiparesis and } \\
\text { decreased visual acuity }(n=2) \text {; MSP with } \\
\text { decreased hearing acuity }(n=2) \text {; MSP with } \\
\text { bilateral blindness ( } n=1) \text {; MSP with decreased } \\
\text { hearing and visual acuity ( } n=1) \text {; MSP, loss of } \\
\text { sphincter continence and neoplastic pathology } \\
\text { ( } n=1) \text {; Parkinson's disease with MSP and } \\
\text { pneumonia ( } n=1) \text {; MSP and renal failure } \\
\text { ( } n=1) \text { NSD with MSP, hemiparesis, loss of } \\
\text { sphincter continence and decreased hearing } \\
\text { acuity ( } n=1) \text {; cognitive impairment with } \\
\text { aphasia, MSP, loss of sphincter continence and } \\
\text { decreased hearing and visual acuity ( } n=1) \text {; } \\
\text { Parkinson's disease with dementia, MSP and } \\
\text { decreased visual acuity ( } n=1) \text {; and NSD, MSP } \\
\text { and epilepsy ( } n=1)\end{array}$ \\
\hline
\end{tabular}

MSP: Musculoskeletal pathology; NSD: Non-specified dementia.

physical plus financial abuse, and 1 of financial abuse, corresponding mostly to nutritional and hygiene neglect, which was followed by medication, health care, rest, affection and housing/ safety neglect.

\subsection{Description of the episode of abuse that motivated the forensic medical examination}

The types of abuse that motivated the report and, subsequently, the forensic medical examination were physical abuse in $85.7 \%$ ( $n=60)$ of the cases, physical and financial abuse in $8.6 \%(n=6)$, and psychological abuse in 5.7\% $(n=4)$. Similarly, in these cases,

Table 4

Background of abuse $(n=52)$

\begin{tabular}{llcc}
\hline & & $n$ & $\%$ \\
\hline Periodicity & Frequently & 27 & $93.1^{\mathrm{a}}$ \\
& Sporadically & 2 & $6.9^{\mathrm{a}}$ \\
Duration & No information & 23 & 44.2 \\
& $<1$ month & 3 & $12.0^{\mathrm{a}}$ \\
& 1 month-1 year & 8 & $32.0^{\mathrm{a}}$ \\
& 2-5 years & 4 & $16.0^{\mathrm{a}}$ \\
6-10 years & - & - \\
Type of abuse & N10 years & 10 & $40.0^{\mathrm{a}}$ \\
& No information & 27 & 51.9 \\
& Physical & 31 & $60.8^{\mathrm{a}}$ \\
& Physical + financial & 9 & $17.6^{\mathrm{a}}$ \\
& Psychological & 8 & $15.7^{\mathrm{a}}$ \\
& Financial & 2 & $3.9^{\mathrm{a}}$ \\
& Physical + sexual & 1 & $2.0^{\mathrm{a}}$ \\
& Without information & 1 & 1.9 \\
& No & 29 & $69.0^{\mathrm{a}}$ \\
& Yes & 13 & $31.0^{\mathrm{a}}$ \\
& No information & 10 & 19.2 \\
\hline
\end{tabular}

\footnotetext{
${ }^{\text {a }}$ Valid percent.
} 
Table 5

Mechanisms of physical abuse $(n=66)$.

\begin{tabular}{lll}
\hline & $n(\%)$ & Type of mechanism \\
\hline Bodily force & $43(72.9)^{\mathrm{a}}$ & $\begin{array}{l}\text { Pounding }(n=11) \text {; pushing }(n=8) ; \\
\text { grasping }(n=2) ; \text { slapping }(n=1) ; \\
\text { kicking }(n=1) ; \text { scratching }(n=1) ; \\
\text { biting }(n=1) ; \text { multiple }(n=17) ; \\
\text { and missing }(n=1)\end{array}$ \\
$\begin{array}{l}\text { Cane }(n=2) ; \text { bottle }(n=1) ; \operatorname{mug}(n=1) ; \\
\text { and bunch of keys }(n=1)\end{array}$ \\
$\begin{array}{c}\text { Restraint and } \\
\begin{array}{l}\text { deprivation } \\
\text { of basic needs }\end{array}\end{array}$ & $1(1.7)^{\mathrm{a}}$ & \\
\end{tabular}

$\begin{array}{ccl}\begin{array}{c}\text { Multiple } \\ \text { mechanisms }\end{array} & 10(16.9)^{\mathrm{a}} & \begin{array}{l}\text { Bodily force (excluding attempted manual } \\ \text { strangulation) and blunt objects }(n=8) \\ \text { and bodily force with attempted manual } \\ \text { strangulation }(n=2)\end{array}\end{array}$

Missing

$7(10.0)$

${ }^{a}$ Valid percent.

neglect was identified in 6 cases of physical abuse and 4 cases of physical plus financial abuse, involving nutritional, hygiene, rest, health care, medication and affection neglect.

Table 5 describes the mechanisms of physical abuse, and the most frequent was aggression with bodily force $(n=51,91 \%)$ and isolated or associated with other mechanisms, namely by pushing ( $n=27,51.9 \%$ ) or pounding ( $n=25,48.1 \%)$. There was no significant relationship between the occurrence of physical abuse and the victims' ( $p=0.800$ ) or abusers' $(0.800)$ sex or the victims' disability degree $(p=1.000)$. Physical abuse resulted in pain in $5.6 \%(n=3)$ of the cases and in minor injuries in $94.5 \%(n=51)$.

The injury distribution is presented in Table 6 . The majority of victims had injuries in multiple locations ( $n=39,63.9 \%)$, and the most frequently observed location was the head and/or neck (75.4\%), particularly the face $(n=35,58.3 \%)$ and skull $(n=20$, $33.3 \%)$, followed by the limbs $(n=34,55.7 \%)$, especially the upper limbs ( $n=27,44.3 \%)$; and torso (26.2\%), where the chest was the most affected ( $n=13,21.3 \%)$. Elders with severe disability had injuries in the head and/or neck more frequently than those with moderate disability ( $88.5 \%$ vs. $65.7 \%, p=0.041$ ), and the same was observed in relation to the presence of injuries in multiple locations. These observations were more frequent for elders with severe disability (76.9\% vs. $54.3 \%$ ), but this relationship was not statistically significant ( $p=0.069)$. In only $6.8 \%(n=4)$ was an organic permanent consequence found (scar).

The described cases of psychological abuse corresponded mostly to insults, humiliation, defamation, threatened aggression or life threats to the victim. Among 23 cases in which psychological consequences of abuse were described, anxiety, anguish or fear were reported in $65.2 \%(n=15)$, physical symptoms of anxiety in $21.7 \%(n=5)$ and a need to escape (leave their house) in $13 \%(n=3)$.

Table 6

Location of injuries according to the victims' disability degree $(n=61)$.

\begin{tabular}{|c|c|c|c|c|c|c|}
\hline & & & Total $n(\%)$ & Moderate $n(\%)$ & Severe $n(\%)$ & $p$ \\
\hline \multirow{2}{*}{\multicolumn{2}{|c|}{ Head and neck }} & Yes & $46(75.4)$ & $23(65.7)$ & $23(88.5)$ & 0.041 \\
\hline & & No & $15(24.6)$ & $12(34.3)$ & $3(11.5)$ & \\
\hline \multirow{2}{*}{\multicolumn{2}{|c|}{ Torso }} & Yes & $16(26.2)$ & $9(25.7)$ & 7 (26.9) & 0.915 \\
\hline & & No & $45(73.8)$ & $26(74.3)$ & $19(73.1)$ & \\
\hline \multirow[t]{4}{*}{ Limbs } & Upper & Yes & $27(44.3)$ & $12(34.3)$ & $15(57.7)$ & 0.069 \\
\hline & & No & $34(55.7)$ & $23(65.7)$ & $11(42.3)$ & \\
\hline & Lower & Yes & $17(27.9)$ & $8(22.9)$ & $8(34.6)$ & 0.311 \\
\hline & & No & $44(72.1)$ & $17(77.1)$ & $27(65.4)$ & \\
\hline
\end{tabular}

Table 7 presents the authorship for the reports (by the victims or by a third person) according to the victims' characteristics. In the majority of cases, the victims pressed charges ( $n=54,77.1 \%$ ). Reporting was performed by professionals ( 1 nurse and 9 day centre attendants) in $14.3 \%$ of the cases, family members in $7.1 \%$ $(n=5)$ and neighbours in $1.4 \%(n=1)$. Victims with severe disability had a third person report the incident more frequently than victims with moderate disability $(p=0.000)$, which was also true for victims with mental disability compared to victims without mental disability $(p=0.000)$. Female victims also had reports performed by a third person more frequently, but this was not statistically significant when the relationship between the victims' sex and the report's author was layered with the degree of disability.

\section{Discussion}

Considering that disability is a recognised risk factor for abuse and that $50 \%$ of the Portuguese elders report having much difficulty in performing daily living activities, ${ }^{6}$ the $5.5 \%$ of elders with this problem found in the forensic medical sample of 1278 elders allegedly abused by a family member in this study seems to be a clear underestimation. This may be related to the difficulties that these people have in disclosing their victimisation and the difficulties that professionals (namely health professionals) have in both detecting and reporting these cases.

\subsection{Victims' socio-demographic and disability characterisation}

Most social, demographic and health characteristics of the elderly have been considered risk factors for abuse. The observed predominance of female over male victims in our study is not explained by the sex distribution in the general Portuguese population where $52 \%$ are women. ${ }^{6}$ Previous studies in frail or hospitalised elders, ${ }^{21,22}$ as well as in elders in the general population, ${ }^{1}$ have reported similar results, suggesting that being female is a risk factor for abuse.

As expected, senior elders had a higher proportion of severe disability than the younger ones. In Portugal, the most frequently reported difficulties in daily living activities among people over the age of 65 are: walking (27\%), bathing and dressing (14\%), seeing (19\%), hearing (15\%), memory and concentration (15\%), and understanding and making themselves understood $(10 \%) .{ }^{6}$ This is consistent with our study's results in which motor disabilities were the most frequently reported, which was followed by mental and sensorial disabilities. Many studies on the abuse of elders with disabilities focus on elders with mental disability, and the reported prevalence of abuse is between $37 \%$ and $62 \%{ }^{23}$ According to a systematic-review and meta-

Table 7

Report authorship according to the victims' characteristics.

\begin{tabular}{|c|c|c|c|c|c|}
\hline & & & $\begin{array}{l}\text { By the victim } \\
n(\%)\end{array}$ & $\begin{array}{l}\text { By another } \\
\text { person } n(\%)\end{array}$ & $p$ \\
\hline \multicolumn{3}{|l|}{ Total } & $54(77.1)$ & $16(22.9)$ & - \\
\hline \multirow{2}{*}{\multicolumn{2}{|c|}{ Victims' sex }} & Female & $29(65.9)$ & $15(34.1)$ & 0.003 \\
\hline & & Male & $25(96.2)$ & $1(3.8)$ & \\
\hline \multirow{2}{*}{\multicolumn{2}{|c|}{ Degree of disability }} & Moderate & 37 (94.9) & $2(5.1)$ & 0.000 \\
\hline & & Severe & $17(54.8)$ & $14(45.2)$ & \\
\hline \multirow[t]{6}{*}{ Type of disability } & \multirow[t]{2}{*}{ Motor } & Yes & $41(75.9)$ & $13(24.1)$ & 0.748 \\
\hline & & No & $13(81.3)$ & 3 (18.8) & \\
\hline & \multirow[t]{2}{*}{ Mental } & Yes & $6(35.3)$ & $11(64.7)$ & 0.000 \\
\hline & & No & $48(90.6)$ & $5(9.4)$ & \\
\hline & \multirow[t]{2}{*}{ Sensorial } & Yes & $14(87.5)$ & $2(12.5)$ & 0.329 \\
\hline & & No & $40(74.1)$ & $14(25.9)$ & \\
\hline
\end{tabular}

a Statistical significance lost when layered with the degree of disability. 
analysis of observational studies, compared with non-disabled individuals, the crude odds ratio for the risk of violence against adults with mental illness $(\mathrm{OR}=3.86)$ or cognitive impairment $(\mathrm{OR}=1.6)$ is higher than that for adults with non-specific impairments $(\mathrm{OR}=1.31) .{ }^{10}$ Comparing these studies with ours, the proportion of elders with mental disability may appear lower than expected, which could be explained by a decreased frequency of reporting. Compared with other groups of elders with disability, those with mental disability have a higher probability of: (a) not understanding that they are being abused; (b) not knowing how or where to make the report; and (c) not being believed when they disclose the abuse. It is therefore possible that the proportion of elders with mental disability is decreased compared to elders with other types of disability, even though a higher proportion of the reports in this group of elders were made by a third person than in other groups. This higher proportion of reports made by a third person may be explained by the social belief that elders with mental disability are less capable of deciding for themselves whether to report an abuse. The observed frailty among elders with severe disability may also explain their higher proportion of reports being made by a third person than those with moderate disability.

\subsection{Socio-demographic characterisation of the alleged abuser}

In our study, abusers were predominantly male. This finding is in accordance with a study of cases of elder abuse performed in the United States ${ }^{4}$ and a study of abuse in elders with cognitive impairment. ${ }^{23}$ However, there are also studies that do not support these data, indicating that male sex of the abuser is not a risk factor. ${ }^{12}$

Information on the offenders' professional occupation was given by the victims or their representatives in few of the reports, raising the possibility of bias. Still, the abusers seemed to spend more time at home because they were either unemployed, retired or had no professional occupation. It was also noted that most offenders cohabited with the victim, raising the possibility of spending more time together. In addition to co-habitation being considered a risk factor for elder abuse, ${ }^{1}$ taking care of elders with disability may further increase the stress and burden on the abuser, which are also considered to be risk factors in studies of elders who require assistance with daily living activities or dementia. ${ }^{12}$

Supporting previous data, both in elders in general ${ }^{2,4}$ and in frail elders, ${ }^{22}$ almost half of the forensic medical reports in our study referred to victims' children as the alleged abusers. However, many studies state that the most frequent abusers are the victims' partners, ${ }^{15,21,24}$ corroborating the observation that among cases of married victims, their partners were the abusers in $50 \%$.

Scarce information on substance abuse or psychiatric illness, recognised as risk factors in the literature, ${ }^{1,3,25}$ was obtained among the forensic medical reports. In a study of patients with Alzheimer's disease, caregivers with alcohol issues were 3 times more likely to use physical violence. ${ }^{26}$ In studies of elders requiring assistance with daily living activities and elders with dementia, psychiatric illness or psychological problems were considered risk factors for abuse. ${ }^{12}$ Despite the scarce numbers of reports providing that type of information, a great proportion of them referred to the presence of substance abuse or psychiatric illness affecting the abusers, which is in accordance with the literature. Still, this proportion can be increased because there may be a tendency for medical examiners to not systematically ask in the routine forensic history whether these problems are present and to emphasise them when they are, because these are frequent explanations for abuse according to both perpetrators and victims. The relationship between alcohol problems or psychiatric illness and elder abuse was not confirmed in 2 studies of abuse in elders with dementia. ${ }^{11,27}$

\subsection{Abuse characterisation}

The fact that the majority of forensic medical reports refer to the occurrence of previous episodes of abuse shows the inefficiency of our society in detecting and protecting these victims. Although abuse is repeated, performed in multiple ways and in most cases for many years, the majority of the victims do not disclose it. In the present study, more than half of the forensic medical reports with a history of abuse had no previous reports. Of those who had previously made reports, more than half were made by a third person. Underreporting by the victims may occur for various reasons, including the following ${ }^{2,28}$ : (a) not being aware of being victims or feeling that the abuse is deserved because they see themselves as a burden to their caregivers; (b) fear of being displaced from their homes and taken away from their loved ones; (c) fear that their loved ones will get into trouble and that they will lose their caregiving and be neglected; (d) shame over being abused; (e) fear of disbelief; (f) fear of retaliation and increased aggressiveness; ( $g$ ) lack of knowledge of available resources for victim protection; (h) inability to disclose the abuse, either for mental or communication problems, isolation or due to interference from the abuser. For these reasons, it is estimated that only 1 in 6 cases are reported to the authorities. ${ }^{2}$

General cultural disapproval of physical violence, wherein this type of violence is widely exposed in the media, may explain the observed predominance of this type of abuse over other types even though only minor injuries and/or pain were observed in our study's cases. The absence of severe injuries certainly does not mean that there are no severe forms of physical abuse. As shown in a study of hospitalised elders with an abuse or neglect diagnosis in the United States, physical abuse was the second most frequently coded form of abuse, which was only surpassed by nutritional neglect. ${ }^{21}$ Among the cases of our study in which the report was made by a professional, none were physicians and only 1 was a nurse. Therefore, these results most likely reflect the underreporting by health professionals. In fact, although much has been written and spoken about elder abuse, this is still a topic that raises doubts, insecurity and concern among health professionals, resulting in underreporting. Further studies are needed to characterise the reporting habits among the Portuguese health professionals so that this problem can be understood and solved.

The distribution of observed injuries differed from that suggested by a literature review in elder abuse. ${ }^{20}$ That review summarised that the upper limb is the most frequent location for injuries resulting from physical abuse to elders, which is logical considering that most physically abused victims try to defend themselves. Elders with disability, especially those with severe disability such as those observed in our study, may have less capacity to do so. This could explain the presence of injuries in multiple locations in that many cases as well as the predominance of injuries in the head and/or neck instead of the limbs as had been observed in some studies of that review. ${ }^{20}$ Head and neck injuries may be more frequent because these are the most accessible areas, particularly when one is sitting or bedridden, and they are preferential positions for those with significant disabilities.

Psychological abuse (when isolated), the most frequently admitted type of abuse perpetrated by caregivers, ${ }^{8,11,22-24,27,29,30}$ did not represent a significant part of our cases when reported by itself. This could be explained by the underestimation of psychological abuse as a significant or serious form of abuse by many people, especially when compared to a physical type. Another reason is that the police frequently do not direct victims of psychological abuse to forensic medical examinations (and our sample is a forensic sample). 
The literature mentions financial abuse as more prevalent than physical abuse among elders. ${ }^{1}$ However, financial abuse was present in only $8.6 \%$ of our cases. It is possible that these cases are not referred because the victim may feel that the forensic expert is not the appropriate person to whom they should report this type of abuse because it is not directly associated with their health. Another explanation is that the police might not direct financial abuse to a forensic medical examination as described above for the cases of psychological abuse.

Sexual abuse was reported in only 1 case in our sample and was described as an event occurring in the distant past. This type of abuse may be hidden because sex is still seen as a taboo topic in the oldest groups of our society. However, the prevalence of this type of abuse is also low among European countries (0.7\%), ${ }^{1}$ making it difficult to include in a sample as small as ours'. ${ }^{28}$

\section{Conclusions}

From this study, we can conclude:

a) That $5.5 \%$ of victims with disability were observed among all cases of elders who were allegedly abused by family members and who underwent forensic medical examination at the North Branch of the National Institute of Legal Medicine and Forensic Sciences of Portugal, in Porto, may be underestimated;

b) The victims are predominantly female (63\%);

c) Motor disability (49\%) is much more frequent than mental disability (7\%) in our sample of abused elders; however, there may be more significant underreporting in the last group;

d) Elders with severe disability have reports presented by a third person more frequently than elders with moderate disability; the same pattern is true when comparing elders with and without mental disability;

e) The abusers are predominantly male (63\%) and they live with the victims (90\%);

f) Although most abusers are the victims' children (47\%), married victims are most frequently abused by their partners (49\%);

g) Most victims have a previous history of abuse by the same abuser (74\%) with multiple cases extending for many years and with frequent episodes (93\%);

h) Physical abuse is the most frequently reported type (86\%);

i) Victims present with multiple, superficial injuries (64\%), mostly in the head and neck (75\%), which contrasts with other age groups in which the limbs are the most affected areas; these findings may possibly explained by their inability to defend themselves, putting them at a higher risk.

Because this was a retrospective study of forensic medical reports, caution must be taken in generalising our results to the general population of elders with moderate or severe disability.

\section{Conflict of interest}

There are no potential conflicts of interest with respect to the research, authorship, and/or publication of this article.

\section{Funding}

The authors received no financial support for the research or preparation of this article.

\section{Ethical approval}

This study was carried out in accordance with ethical rules. It has not been submitted to Ethical Approval because it was a retrospective review in which no invasive studies were carried out nor was identification of the individuals given.

\section{References}

1. World Health Organisation. European report on preventing elder maltreatment. 2011.

2. Bond MC, Butler KH. Elder abuse and neglect: definitions, epidemiology, and approaches to emergency department screening. Clin Geriatr Med 2013;29(1): 257-73.

3. Yaffe MJ, Tazkarji B. Understanding elder abuse in family practice. Can Fam Physician 2012;58(12):1336-40. e695-8.

4. Krienert JL, Walsh JA, Turner M. Elderly in America: a descriptive study of elder abuse examining National Incident-Based Reporting System (NIBRS) data 2000-2005. J Elder Abuse Negl 2009;21(4):325-45.

5. Cooper C, Selwood A, Livingston G. The prevalence of elder abuse and neglect: a systematic review. Age Ageing 2008;37(2):151-60.

6. Instituto Nacional de Estatística, I.P. Censos 2011 resultados definitivos Portugal. Instituto Nacional de Estatística, I.P; 2012.

7. Anetzberger GJ, Palmisano BR, Sanders M, Bass D, Dayton C, Eckert S, et al. A model intervention for elder abuse and dementia. Gerontologist 2000;40(4): 492-7.

8. Cooper C, Selwood A, Blanchard M, Walker Z, Blizard R, Livingston G. Abuse of people with dementia by family carers: representative cross sectional survey. BMJ 2009;338:b155.

9. Lee M, Kolomer SR. Caregiver burden, dementia, and elder abuse in South Korea. J Elder Abuse Negl 2005;17(1):61-74.

10. Hughes K, Bellis MA, Jones L, Wood S, Bates G, Eckley L. Prevalence and risk of violence against adults with disabilities: a systematic review and meta-analysis of observational studies. Lancet 2012;379(9826):1621-9.

11. Compton SA, Flanagan P, Gregg W. Elder abuse in people with dementia in Northern Ireland: prevalence and predictors in cases referred to a psychiatry of old age service. Int J Geriatr Psychiatry 1997;12(6):632-5.

12. Johannesen M, LoGiudice D. Elder abuse: a systematic review of risk factors in community-dwelling elders. Age Ageing 2013;42(3):292-8.

13. Laumann EO, Leitsch SA, Waite LJ. Elder mistreatment in the United States: prevalence estimates from a nationally representative study. J Gerontol B Psychol Sci Soc Sci 2008;63(4):S248-54.

14. Ferreira-Alves J, Santos AJ. Prevalence study of abuse and violence against older women - Portugal report (AVOW Project). 2011.

15. Biggs S, Manthorpe J, Tinker A, Doyle M, Erens B. Mistreatment of older people in the United Kingdom: findings from the first national prevalence Study J Elder Abuse Negl 2009;21(1):1-14.

16. Lachs MS, Williams C, O'Brien S, Hurst L, Horwitz R. Risk factors for reported elder abuse and neglect: a nine-year observational cohort study. Gerontologist 1997;37(4):469-74.

17. Perez-Carceles MD, Rubio L, Pereniguez JE, Pérez-Flores D, Osuna E, Luna A Suspicion of elder abuse in South Eastern Spain: the extent and risk factors. Arch Gerontol Geriatr 2009;49(1):132-7.

18. Walsh CA, Olson JL, Ploeg J, Lohfeld L, MacMillan HL. Elder abuse and oppression: voices of marginalized elders. J Elder Abuse Negl 2011;23(1):17-42.

19. Dantas S, Santos A, Dias I, Dinis-Oliveira RJ, Magalhães T. Parricide: a forensic approach. J Forensic Leg Med 2014;22:1-6.

20. Murphy K, Waa S, Jaffer H, Sauter A, Chan A. A literature review of findings in physical elder abuse. Can Assoc Radiol J 2013;64(1):10-4.

21. Rovi S, Chen PH, Vega M, Johnson MS, Mouton CP. Mapping the elder mistreatment iceberg: U.S. hospitalizations with elder abuse and neglect diagnoses. J Elder Abuse Negl 2009;21(4):346-59.

22. Anme T, McCall M, Tatara T. An exploratory study of abuse among frail elders using services in a small village in Japan. J Elder Abuse Negl 2005;17(2):1-20.

23. Kishimoto Y, Terada S, Takeda N, Oshima E, Honda H, Yoshida H, et al. Abuse of people with cognitive impairment by family caregivers in Japan (a crosssectional study). Psychiatry Res 2013;209(3):699-704.

24. Wiglesworth A, Mosqueda L, Mulnard R, Liao S, Gibbs L, Fitzgerald W. Screening for abuse and neglect of people with dementia. J Am Geriatr Soc 2010;58(3):493-500.

25. Walsh CA, Yon Y. Developing an empirical profile for elder abuse research in Canada. J Elder Abuse Negl 2012;24(2):104-19.

26. Vandeweerd C, Paveza GJ, Walsh M, Corvin J. Physical mistreatment in persons with Alzheimer's disease. J Aging Res 2013;2013:920324.

27. Cooney C, Howard R, Lawlor B. Abuse of vulnerable people with dementia by their carers: can we identify those most at risk? Int J Geriatr Psychiatry 2006;21(6):564-71.

28. Nobrega Pinto A, Rodrigues F, Dinis-Oliveira RJ, Magalhães T. Sexual offenses against elderly people: forensic evaluation and judicial outcome. J Elder Abuse Negl 2014;26(2):189-204.

29. Cooper C, Selwood A, Blanchard M, Walker Z, Blizard R, Livingston G. The determinants of family carers' abusive behaviour to people with dementia: results of the CARD study. J Affect Disord 2010;121(1-2):136-42.

30. Yan E, Kwok T. Abuse of older Chinese with dementia by family caregivers: an inquiry into the role of caregiver burden. Int J Geriatr Psychiatry 2011;26(5): $527-35$. 